\title{
4
}

\section{Care, Elderspeak, and Meaningful Engagement}

By the time I met Sister Helen, who is pictured in figure 4.I, she had a deteriorative neurological condition that made it nearly impossible for her to speak. She had trouble moving her hands and controlling many of her muscles. She could communicate using the sounds "ah" and " $\mathrm{mm}$," which she could vary in rhythm and prosody. She lived in the infirmary, where nurses and her peers bathed her, changed her clothes, took her out of bed, sat her in a chair, changed her clothes again, and moved her back into bed at night. Each day one of the sisters spoon-fed Sister Helen her meals.

Imagine, for a moment, interacting with Sister Helen. What would you say? What would you be able to talk about or do together? How would you interact with someone who could not communicate with you in ways that you could understand? In the United States, many people like Sister Helen become socially isolated. When friends, family, or caregivers interact with people who cannot communicate fluently, they often resort to elderspeak, a simplified register of speech that resembles baby talk, the singsong manner in which many people use to speak to infants (Grainger 1993). ${ }^{1}$

In the United States and western Europe, older adults who need daily care spend much of their time alone, in an isolated environment in which they have little social interaction (Grainger 1993). Linguist Karen Grainger has found that even when older adults are communicatively engaged, their contributions are often ignored or even demeaned. This bleak social landscape, with few "confirmative and stimulating adult-to-adult encounters," is unfortunately common 


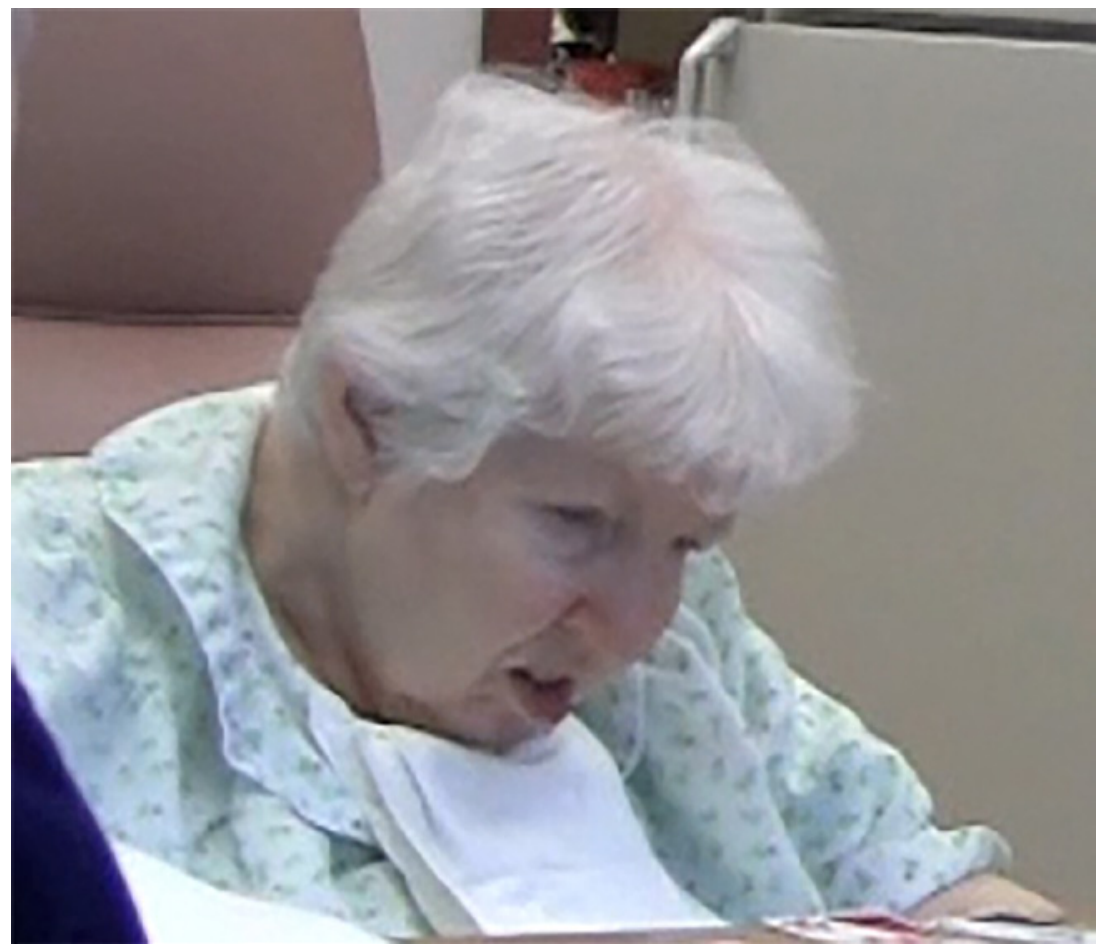

FIG. 4.1 Sister Helen. (Photo by the author)

and has been found by researchers to negatively affect elderly individuals' cognitive function (Williams 2011, 9). Grainger suggests that the "most important move" in elder care would be "for elderly long-term care to take place in an environment in which the status of caring (vs. curing) is elevated to the level of a valued occupation and skill" (1993, 433). When she wrote this, Grainger anticipated a change in aging policy by two decades. Indeed, since then, isolation and loneliness have been identified as major risk factors affecting physical and mental health in older adults (Ong, Uchino, and Wethington 2016). A number of studies have linked social isolation with shorter life spans, depression, problems in cardiovascular health, and lower reported well-being (Courtin and Knapp 2015; Ong, Uchino, and Wethington 2016). Grainger, in the quote above, suggests that instead of "curing" elders in isolation, institutions must focus on care and interaction.

Nuns offer one model of this approach, as the convent provides remarkably robust social support. To some extent Grainger's call to increase meaningful communication with older adults can be addressed by simply increasing the number of opportunities older adults have to engage with each other and with family, community members, and care providers. This, at its essence, is a matter 
of facilitating copresence, allowing people to be together. The one major challenge to this is the stigma attached to aging in the United States, the notion that older people in general are less capable of engaging in rich communication than are other adults. One step to reducing elderspeak in contexts with communicatively competent older adults may require a reexamination of this stigma.

Elderspeak has a handful of identifiable linguistic features, including slow speech rate, exaggerated intonation, elevated pitch and volume, simplified vocabulary, reduced grammatical complexity, changed affect, collective pronoun substitutions, diminutives, and repetition (Nussbaum et al. 1996; Ryan, Maclean, and Orange 1994; Williams 201I). A majority of older adults report that elderspeak feels patronizing and disrespectful. It has been found to result in negative self-assessment (Edwards and Noller 1993; Gould, Saum, and Belter 2002; Kemper and Harden 1999; Ryan, Hummert, and Boich 1995; Williams, Kemper, and Hummert 2003). Even more concerning, elderspeak has been linked to social isolation and cognitive decline (Salthouse 1999; Williams 20II), negative behaviors (Ryan, Maclean, and Orange 1994), and an increase in resistiveness to care (Cunningham and Williams 2007; Williams et al. 2009; Williams et al. 2016). There have been some successful interventions to train caregivers to avoid using many of the elements of elderspeak (see, for example, Williams 2013 and Williams et al. 2016). They have, however, failed to eliminate two important elements: a tendency to use simple vocabulary and reduced grammatical complexity (Corwin 2017, 2), both of which are important for maintaining cognitive and emotional well-being (Salthouse 1999; Savage, Piguet, and Hodges 2015).

Avoiding elderspeak and speaking with the same linguistic complexity and richness that individuals use with other adults should not be too difficult when individuals are interacting with communicative older adults. Yet elderspeak can be significantly harder to avoid when an older adult has linguistic difficulties that result in communicative breakdown. For instance, if an individual cannot or does not respond when he is addressed or if his responses are not clear or do not correlate with the topic of conversation, it can be difficult to engage in interaction without communicative breakdown. These breakdowns can be confusing or off-putting at the least and can be awkward, emotionally painful, or bring shame if the older adult becomes aware and/or frustrated with his inability to communicate. For instance, not being able to appropriately answer a question or collaborate in a simple two-part sequence can be challenging for both parties. Two-part sequences often require a specific type of response. For instance, the greeting "Hello" requires a type of response such as "Hello," rather than "Fourteen," and "Nice to see you" requires a particular type of answer, such as "Nice to see you, too" rather than silence or a non sequitur such as 
"Window." If one of the participants is not able to participate in a culturally appropriate way, the exchange can become stressful for both interlocutors. Interacting with someone who has communicative challenges can sometimes lead caregivers or others to engage with individuals using only simplified speech or, in an effort to avoid discomfort, to begin to avoid interaction all together.

When I was in the convent, I noticed that, despite the presence of many sisters who had significant communicative difficulties, I heard almost no elderspeak. In fact, only one of the dozens of sisters I saw interacting with older sisters in the infirmary regularly used elderspeak at all. Remarkably, the sisters whom I witnessed interacting with those who had communicative difficulties engaged them using rich, linguistically complex conversations, even though the sisters could not always respond in kind. This is a remarkable achievement. Imagine, for a moment, the linguistic difficulty of this task. Most of the typical ways we interact with individuals involve mutual active and relevant participation. With the exception of reading texts or listening to monologues, communication is usually a dance in which both parties participate.

How did the nuns engage their peers who had challenges communicating in rich, linguistically complex conversations? The data for this chapter come from my time shadowing Sister Irma, Sister Rita, and other nuns who provided pastoral care to the older sisters in the infirmary. In care interactions, I found that these sisters used three linguistic strategies to engage their peers in rich interaction without speaking down to them or using elderspeak: blessings, jokes, and narratives.

\section{Blessings}

First, the visiting sister prayed. On one of the first days I followed Sister Irma room to room in the infirmary, she told me that even though she could not massage some of the sisters' feet, which was something she regularly did for most of the nuns, she always went in to check on them. I watched as she moved down the linoleum hallway, walking into each open doorway. When she encountered a sister who could not speak or move, she reached out her thumb and drew a cross on that sister's forehead and spoke a blessing, such as "Jesus told me to tell you that he loves you."

On one such visit, Sister Irma bent over the armchair Sister Jeanne was sitting in and drew the cross on the sister's head (see fig. 4.2).

Here, she spoke a blessing. As in chapter 3 , the interactions are transcribed using transcription conventions that provide detail into not only what words were spoken but also how they were spoken. The conventions are explained in the appendix. 


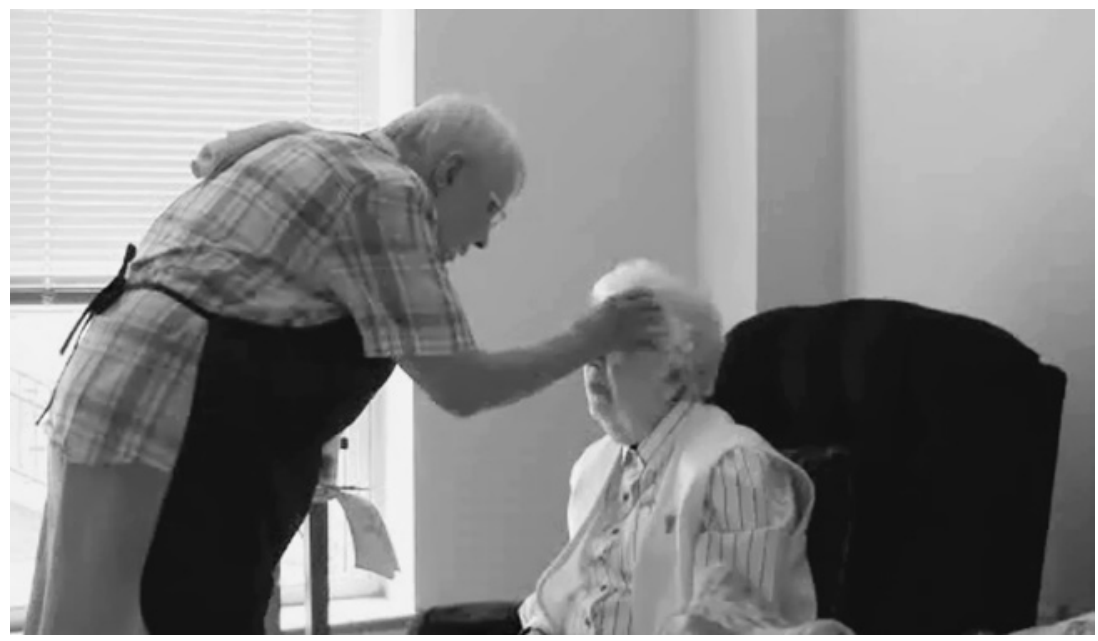

FIG. 4.2 Sister Irma drawing the sign of the cross. (Photo by the author)

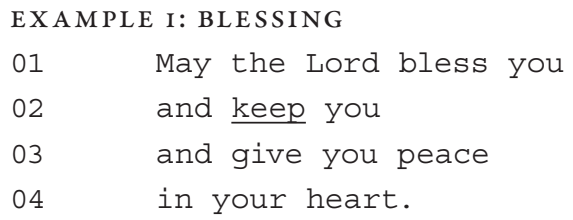

Although the blessing was short, it nevertheless demonstrates relative grammatical complexity, with multiple clauses that engaged Sister Jeanne without requiring her to respond. Because blessings are structured such that the direct recipient is the divine and not the human subject of the prayer, the interaction would be communicatively "successful" whether or not Sister Jeanne responded.

While Sister Jeanne had the opportunity to be engaged in meaningful interaction, she was not required to respond in a particular way. Thus, whether she was silent or responded, she could be a "successful" participant in a rich and meaningful interaction.

Sister Irma often requested blessings from the older sisters in the infirmary, including those who had limited communicative ability. For instance, in the following exchange, Sister Irma walked into Sister Helen's room. Sister Helen, whom we met at the beginning of this chapter, had a deteriorative neurological disorder which limited her ability to speak clearly. She seemed to understand language when she was spoken to and she could produce a few sounds such as "ah" and "mm" with some variation in prosody by increasing and decreasing the pitch contours and rhythm of these sounds. It was extremely difficult to make out what she was trying to say, which made communication challenging. 
After Sister Irma massaged Sister Helen's feet and washed her hands, she asked Sister Helen if she would like a blessing. Sister Helen responded with "mm." As we saw in the exchange above, the blessing afforded a rich linguistic exchange even if the recipient could not produce clear words. After her blessing, Sister Irma asked Sister Helen to bless her in return. As I sat on Sister Helen's bed, holding my audio recorder, I remember being a bit stunned by this request. How could she ask someone who could produce only a variation of moans to provide a blessing for her?

I watched as Sister Irma placed Sister Helen's hand on her forehead and listened while Sister Helen blessed her:

EXAMPLE 2: SISTER HELEN'S BLESSING

\section{Participants}

SI: Sister Irma

SH: Sister Helen

AC: Anna Corwin (author)

01 SI: There ya go: :

$02 \quad(6.0)$

03 You ready for your blessing?

$04 \mathrm{SH}$ : Ahhhhhsh.

05 SI: Okay.

$06 \quad(5.0)$

07 May the Lord bless you and keep you. May He give

08 you courage to live each day knowing He is with

09 you.

10 Amen.

11 (1.5)

$12 \mathrm{SH}:$ Ahhh.

13 SI: And now I'd like to have a blessing, okay?

14 Can you bless me?

$15 \mathrm{SH}:$ Mmmhhh, mmhh, mmhhh, mmhh, mmmhhh,

16 mmmh ahhh.

17 Mhh mm-hmm, mmmmm, mm-mm.

18 SI: Amen. Thank you.

$19 \mathrm{SH}$ : Ahh.

After the blessing was completed, Sister Irma invited Sister Helen to give me a blessing. She called me over and placed Sister Helen's hand on my forehead (line 22).

$20 \mathrm{SI}$ : Would you like to give Anna a blessing too?

21 AC: I would love that if- 


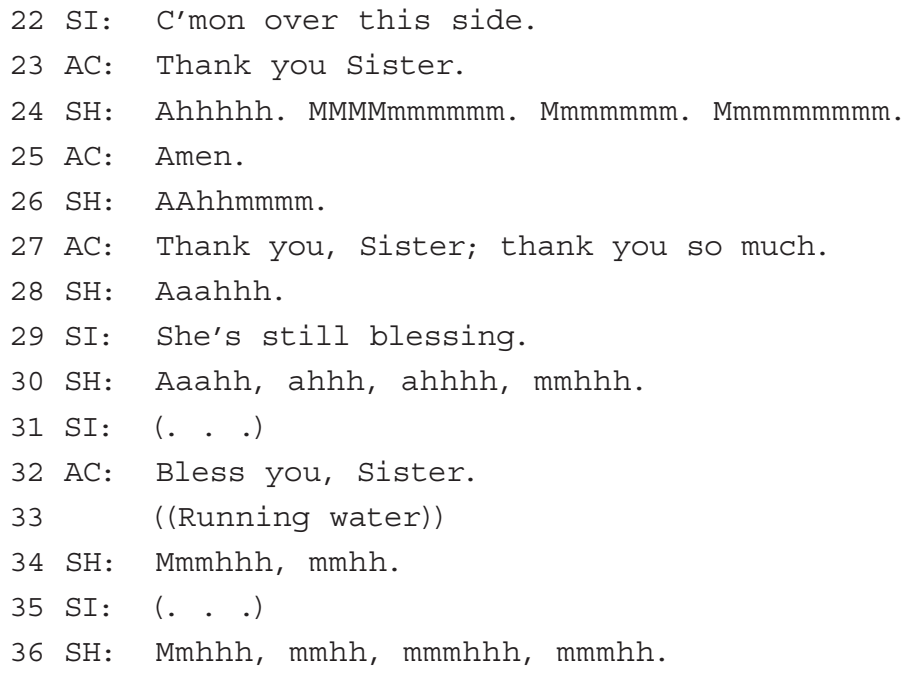

Being a non-Catholic and not skilled in receiving blessings, I thanked Sister Helen (line 27) before she had finished. She ignored my blunder and kept going, and Sister Irma kindly explained to me that she was still in the middle of the blessing (line 29).

Even though Sister Helen was the one who could use only a few sounds and variation in prosody to communicate, it was me, the non-Catholic, who was the only incompetent participant. As was typical in my first few months at the convent, I had not yet learned the patterns of prayer well enough to participate fluently, and as usual, the nuns gracefully alerted me to my errors and helped me learn.

Despite her limited communicative ability Sister Helen, unlike me, was able to be a competent participant in the blessing, not only as Sister Irma engaged her in dynamic interaction but also as she produced her own prayers. The fact that Sister Irma and I could not understand the prayer did not matter for the communicative success of the interaction, since the primary recipient was God. Blessings, therefore, allowed for individuals like Sister Helen to participate as both a listener and a speaker in linguistically rich, meaningful interaction free of the trappings of elderspeak.

\section{Jokes}

Sister Irma had a remarkable array of jokes. There was the one about the donkey on whom Jesus rode into Jerusalem who, upon hearing the cries of the people-“Hosanna! Blessed is he who comes in the name of the Lord!"trotted a little bit more proudly, thinking to himself, "My name must be Hosanna!" And there was the one about the old couple who sat in the kitchen, and one morning the man asked the woman "Honey, do I wear boxers or briefs?" 
and she answered, "Depends." No matter how many times I heard her jokes, Irma's impish smile and chuckles always filled me with a lightness and joy.

Dementia can be terrifying as it renders familiar landscapes unfamiliar and steals memories and familiar faces. It can take the humdrum of quotidian conversation and create a minefield from it. One morning, as I walked the hallways after Mass, I saw Sister Julette walking toward me. Sister Julette was one of the few sisters who still wore a habit with a veil. I stopped to make small talk and asked her if she had enjoyed the Mass. The muscles in her face went slack and a look of fear, if not terror, washed over her. Had Mass already happened? She was heading there and could not remember if she had already been or if she had overslept and forgotten. As I tried to reassure her that it was okay, Sister Julette became increasingly lost in a confusion and a moral panic that she had done something wrong by (unintentionally) skipping Mass. Another sister soon saw us in the hallway and with a much more forceful authority reassured Sister Julette that everything was all right.

This moment, as my seemingly mild small talk created such suffering in a woman who could no longer rely on her sense of time and memory to get herself to Mass, brought home to me how devastating dementia can be. The routine stability of time and space and the familiarity of the world could become corrupted and confused. This story ended well enough - the sisters quickly coordinated efforts so that in the future Sister Julette always had someone come by to accompany her to Mass - but it made me aware that even routine daily communication like the small talk I tried to engage in with Sister Julette could become quite difficult for people experiencing dementia and other pronounced cognitive decline.

In the following interaction, Sister Irma, who had known Sister Julette for most of their lives, entered Sister Julette's room to provide a foot massage. Sister Julette began the exchange by remarking that she had forgotten Sister Irma's name. The fact that she said "and I forgot" indicates that she was aware that she had once known and perhaps should have known Sister Irma's name. This was a potentially delicate exchange as it brought to the fore the fact that Sister Julette was rapidly losing her memory, but Sister Irma skillfully transitioned to joking.

EXAMPLE 3: JOKING

Participants

SI: Sister Irma

SJ: Sister Julette

$01 \mathrm{SJ}$ : And I forgot your name.

$02 \mathrm{SI}$ : Irma.

$03 \mathrm{SJ}$ : Irma.

$04 \mathrm{SI}$ : We used to play cards together.

05 SJ: Irma. . . ? 
06 SI: Coleman.

07 SJ: Coleman.

08 SI: Sister Irma. Sometimes some of 'em call me Fatty

09 Irma,

10 or Ratty Irma, or Bratty Irma.

11 I get all kinds. But then I give 'em right back.

12 (heh. heh. hheeh)

13 SJ: You don't pay attention to any of 'em.

14 SI: Nah, it's fun. They're just teasing me. Right?

15 You learn how to take a teasing.

The joking that Sister Irma used here moved the conversation away from the potentially upsetting reminder that Sister Julette had forgotten the name of someone she had known for decades. It also allowed the two nuns to communicate using linguistically rich and complex language (Corwin 20I8). In addition, the joking allowed Sister Julette to join in the interaction while not requiring her to contribute in a specific way.

In this exchange, Sister Julette participated by joining Sister Irma in laughter (line 12) and through speech (line 13), but her participation was not required for the interaction to unfold coherently. This is an important feature of joking, a genre of speech that allows participants the opportunity to engage linguistically, but even if they say nothing, or only smile or chuckle, participants such as Sister Julette would be included in a linguistically rich communicative interaction.

\section{Narratives}

Another strategy that the sisters used in the infirmary was the recounting of narratives. This strategy was similar to joking in that it allowed the sisters to engage in rich, linguistically complex interaction with other sisters who might not have been able to respond to other types of communication. Narratives allowed rich and varied engagement without requiring a specific response from an interlocutor. They did, however, allow the communicative partner to engage in a subsequent story if she chose to. In this way, much like blessings and jokes, narratives allowed for linguistic engagement with people who had limited communicative ability while simultaneously providing a very low risk of communicative breakdown.

In the following example, which occurred a few minutes after the joke mentioned above, Sister Irma was massaging Sister Julette's feet. She raised a potentially problematic topic, the recent death of a mutual friend, a peer in the convent whom Sister Julette had known well but might have forgotten. In this interaction, we can see that the question-and-answer formulation at the beginning (lines OI-04) was problematic, as Sister Julette had forgotten that her 
friend Sister Alice had died. Sister Irma responded to the tension created in this question-and-answer sequence by beginning a narrative.

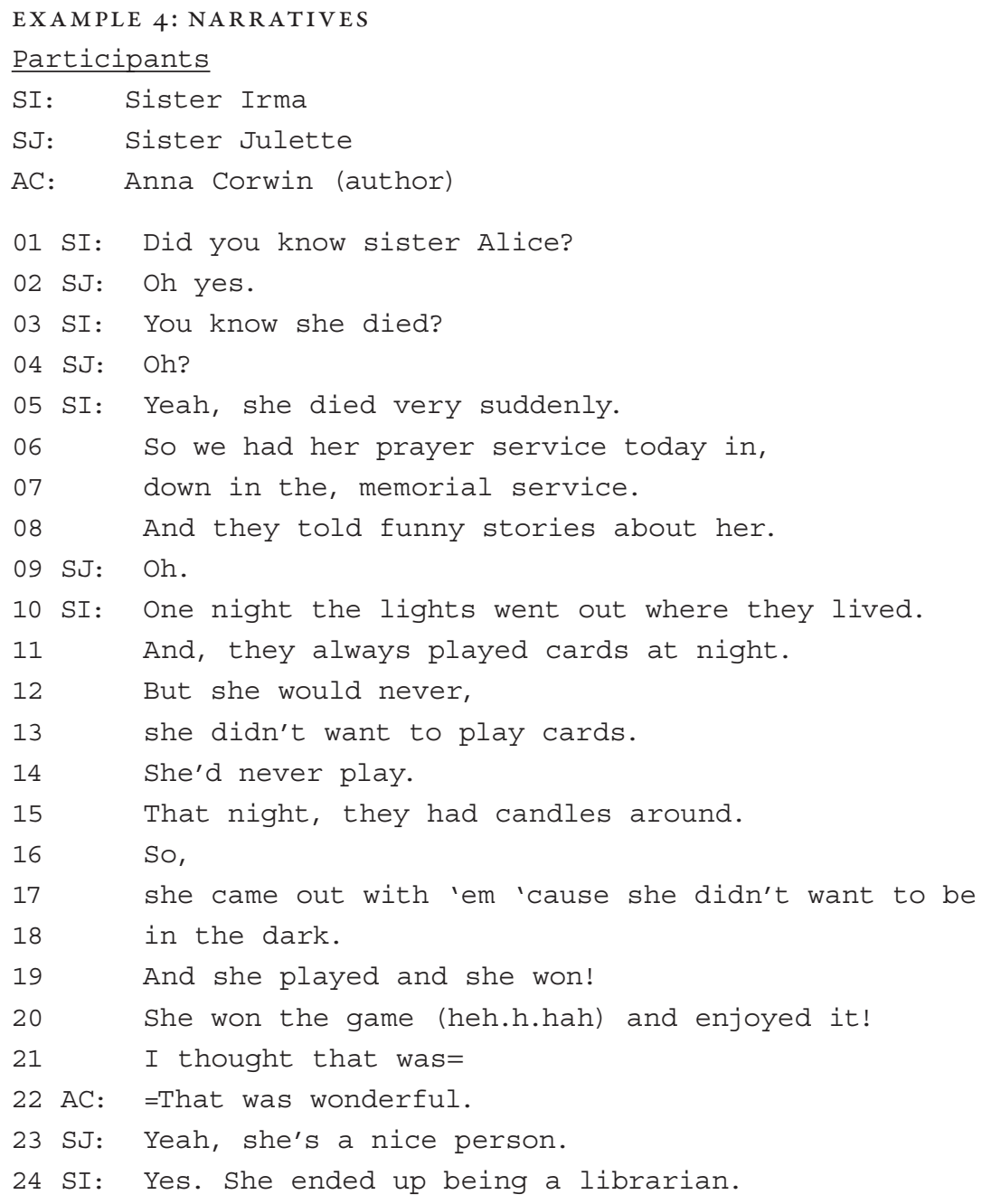

The narrative not only resolved the social tension that was introduced in the question-and-answer sequence (in lines OI-04) but also allowed Sister Irma to communicate using linguistically complex language without requiring Sister Julette to say anything specific. Sister Julette did not have to affirm or deny any particular memories and could successfully participate in the interaction whether or not she remembered or could produce specific memories or language. The structure of the narrative allowed her to participate if she chose to, as she did in line 23, "Yes, she's a nice person," but the interaction would also have been communicatively successful without her participation. In this way, 
narratives, like blessings and jokes, allowed the sisters to interact with their peers who had communicative limits using meaningful, linguistically rich and grammatically complex language.

\section{Social Engagement: Playing Cards Together}

The nuns not only engaged each other in complex linguistic interactions while they provided structured care, as Sister Irma did in the instances above, but also in meaningful social interactions whose purpose was not explicitly to provide care. For instance, Sister Helen, whom Sister Irma had asked to pray for me despite her productive aphasia, was fed, dressed, bathed, and physically cared for; but she was also engaged as a meaningful participant in everyday social activities. Almost every evening, after the sisters had finished supper, two nuns, Sister Polly and Sister Marie, would play cards with Sister Helen.

The idea that Sister Helen, with limited ability to express herself verbally and move physically, would be able to engage in a card game might seem farfetched. One might picture, for instance, a game in which Sisters Polly and Marie played at playing cards with Sister Helen to humor her or express care for her. One could imagine a unidirectional activity in which Sister Helen's peers played with her to amuse or edify her, but this was not what happened. The card game was not an activity set up to care for Sister Helen. This was an honest and remarkably competitive game in which all three women were engaged in a meaningful activity together.

Before we turn to examine how Sisters Polly and Marie engaged Sister Helen in a meaningful game of cards, it is important to note that they engaged her in this activity in the first place. This is further evidence of the pattern in the convent in which individuals were valued even after they were no longer active or productive adults. Although Sister Helen's physical and communicative abilities were limited, her peers continued to treat her as a valuable member of the community. Rather than being segregated from the ongoing activities in the convent, Sister Helen continued to be invited to participate in social activities such as the lively card games that many of the sisters played each night. This is evidence of the ideology in the convent that all persons were valuable and meaningful members of the community. Echoing chapter 2, this is another example of how, through their everyday interactions, the sisters communicated to each other the idea that every person was valuable at every stage of the life course. By publicly engaging sisters like Sister Helen in meaningful social activities, they were communicating to each other and to younger peers the community expectations about aging and engagement across the life course. 
Beyond noting that community members engaged peers like Sister Helen in this way, one must ask how the two sisters played a meaningful and relatively competitive game of cards with Sister Helen. The exchange that follows provides a glimpse into their interactions. What is remarkable about the way in which they engage with Sister Helen is that the sisters provided just enough scaffolding to allow Sister Helen to maximize her participation, allowing her to participate to the maximum of her ability. ${ }^{2}$

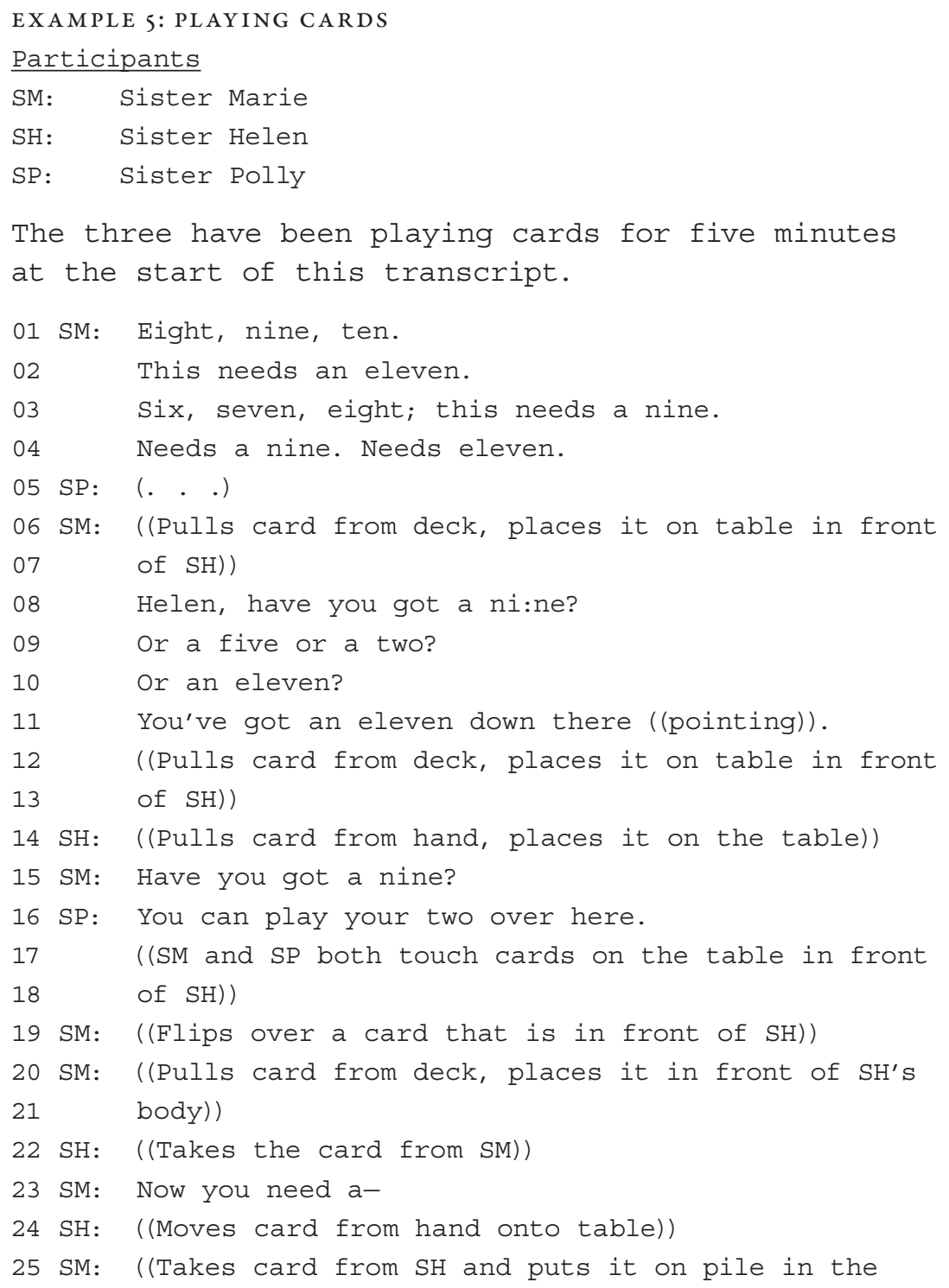


In the first five lines of the transcript Sister Marie provided just enough verbal context to allow Sister Helen to engage by listing the cards aloud. When Sister Helen did not make a move, Sister Marie asked her explicitly if she had the card that was needed (line o8). When Sister Helen did not respond, she provided even more direct scaffolding, pointing out that Sister Helen had a card that would play (line ir). She then pulled another card from the deck and placed it in front of Sister Helen. During this sequence, Sister Helen was relatively still and remained slumped over, with her hands under the table. It was not immediately apparent to me that she was listening or attending to the ongoing game. An uninformed viewer of the video recording might have mistaken her for someone who was sleeping. Then, for anyone watching who did not know Sister Helen, something remarkable happened. In line I4, Sister Helen's hand slowly emerges from under the table and she places a card from her hand on the table demonstrating that she was not only attending to the game but was engaged as an active participant.

In the following lines, Sisters Polly and Marie continued to provide just enough scaffolding to allow Sister Helen to participate without going so far as to do things for her or to limit her possible actions in any way. In each moment, her peers allowed Sister Helen to maximize her participation before providing assistance. In line 29, when Sister Helen reached for a card that would not "play" with the cards that were out, instead of making a play for her, Sister Marie simply placed her hand over the pile Sister Helen was moving her hand toward. This allowed Sister Helen to correct course on her own. A moment later, Sister Helen reached out to place a card on a pile on the table but could not reach the 


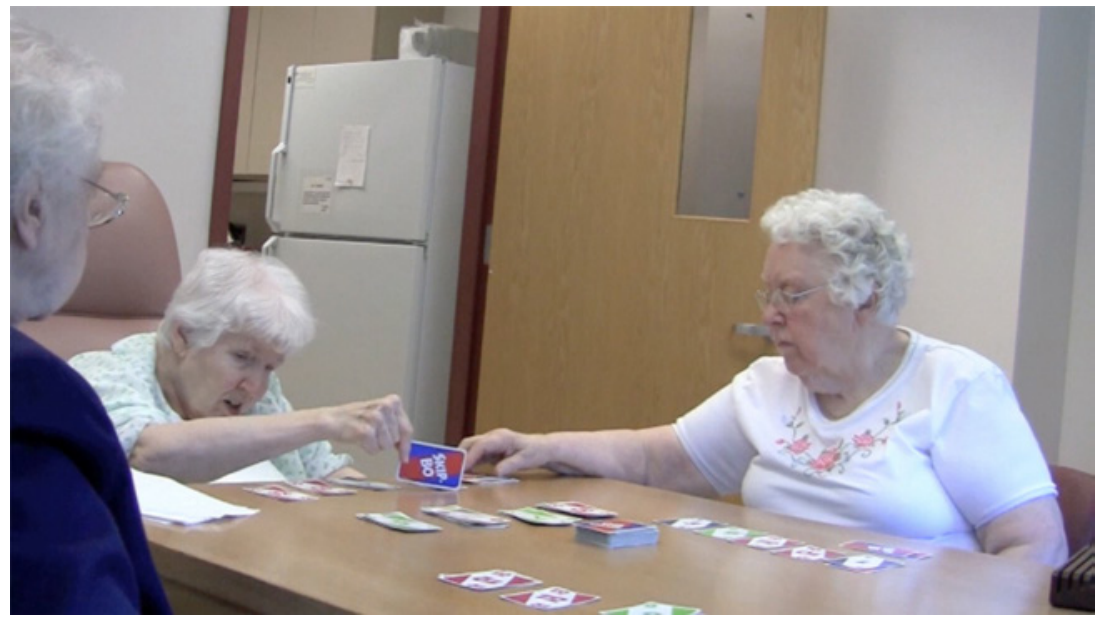

FIG. 4.3 Sister Helen reaches out to place a card on a pile on the table. (Photo by the author)

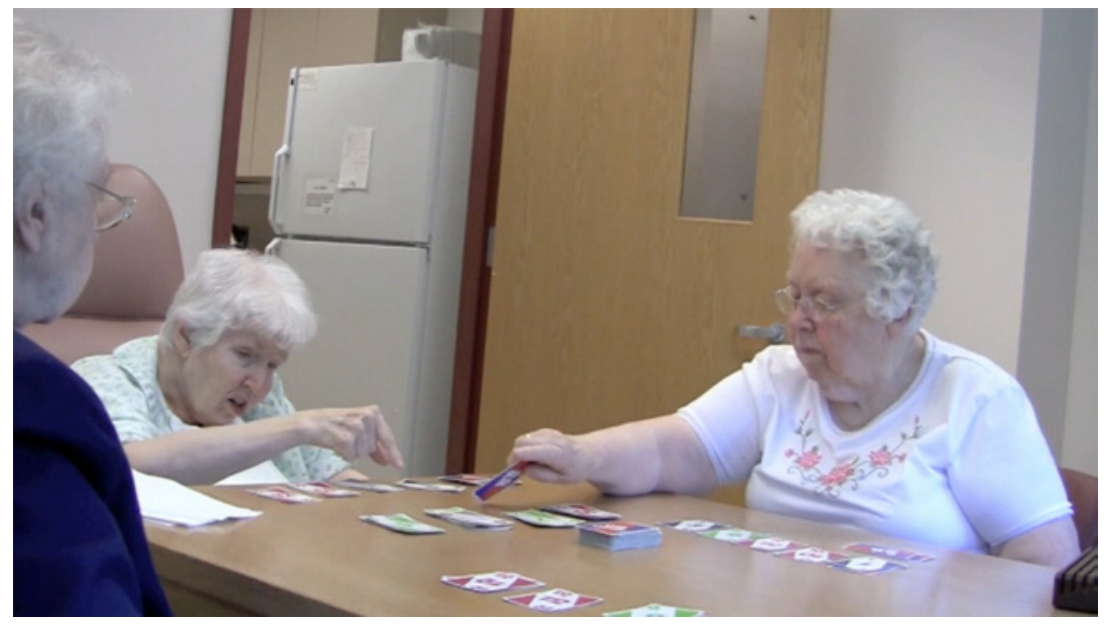

FIG. 4.4 When Sister Helen has maximized her reach, Sister Marie completes the action. (Photo by the author)

full distance (see fig. 4.3). Just at the moment when Sister Helen had maximized her reach, extending her arm with the card, Sister Marie seamlessly took hold of the card and continued the flow of action, placing it on the pile Sister Helen had been moving it toward (see fig. 4.4).

Watching Sisters Marie, Polly, and Helen play cards together felt to me like watching a well-choreographed dance. Sister Helen was included as a meaningful participant, and the other sisters were present to assist her 
when she came to the edge of her physical capacity. The sisters never stepped in too soon, which would have limited Sister Helen's full participation, but neither did they leave her hanging, which would have interrupted the flow of the game. Sister Helen moved slowly, but her peers consistently waited until she had maximized her action before stepping in, and they were attentive enough that when she reached the edge of her possible participation, they were there to finish the action or provide scaffolding to allow for a subsequent action.

Much like the blessings, jokes, and narratives that Sister Irma and others engaged in with their peers, social interactions like this card game allowed for sisters who were experiencing age-related decline to participate meaningfully in dynamic social interaction. Notably, these interactions were not unidirectional activities in which a caregiver attended to someone who could no longer care for herself. Instead, these activities were meaningful joint activities in which peers engaged each other. By continuing to engage sisters like Sister Julette and Sister Helen in social activities, the community provided opportunities for aging sisters to be engaged physically and linguistically to the maximum of their ability in meaningful cooperative activities.

\section{Summary: Meaningful Engagement}

The linguistic techniques that the nuns used in the convent offered opportunities for each sister to listen and produce meaningful interaction and to be engaged in lexically and grammatically rich conversation without pressure to engage in ways that were beyond her ability and without risking failure. The sisters skillfully engaged their peers with blessings, jokes, and narratives that allowed them to engage meaningfully even when their peers could not respond in kind. In addition, as we saw with Sister Helen's card game, they also provided opportunities for sisters to maximize their possible participation, to continue to engage meaningfully, and therefore not risk atrophy of their social and linguistic abilities or isolation.

Given how detrimental elderspeak can be for individuals' physical and emotional health, these examples illustrate important alternatives. The sisters' communicative strategies not only avoided elderspeak but engaged communicatively compromised older adults as respected peers, exposing them to linguistically complex, grammatically rich interaction that has been documented to help maintain emotional and cognitive health.

This concludes part I of the book, which has focused on the ways in which the nuns' ideologies and practices fit into the "successful aging" paradigm-a paradigm I have critiqued for its antiaging assumptions. In part II we will look at how the nuns' practices and ideologies have changed over the sisters' lifetimes. As we will see in the chapters 5-7, the major institutional changes that occurred 
in the Catholic Church following Vatican II have had significant impacts on the nuns' lives and therefore on their linguistic practices and their experiences in the world. Chapter 5 examines how prayer practices drastically changed between the time nuns entered the convent and the time I arrived; the chapter will look at how the changes in the structure of prayer shaped how the nuns experienced their own bodies, illness, and pain. Chapter 6 will then look at how ideologies of pain have changed over the same time period, and chapter 7 will look at how Vatican II shaped some of the nuns' theological practices, including the meaning of their vows and their relationship with self-determination and material goods. This, too, had implications for how the nuns experienced aging.

Together the chapters in part II look to the institutional event that changed the course of the nuns' lives, Vatican II, detailing how their habitual practices were reshaped. We will begin to see how the transformation has led to a particular moment in time in which we see the nuns and their attitudes about and experiences of aging. We will see that cultural practices are not fixed but always in contact with the ever-changing political, historical, and social structures in the world. 
